\title{
Lisa Dicaprio, The origins of the Welfare State. Women, work and the French Revolution
}

\section{Caroline Fayolle}

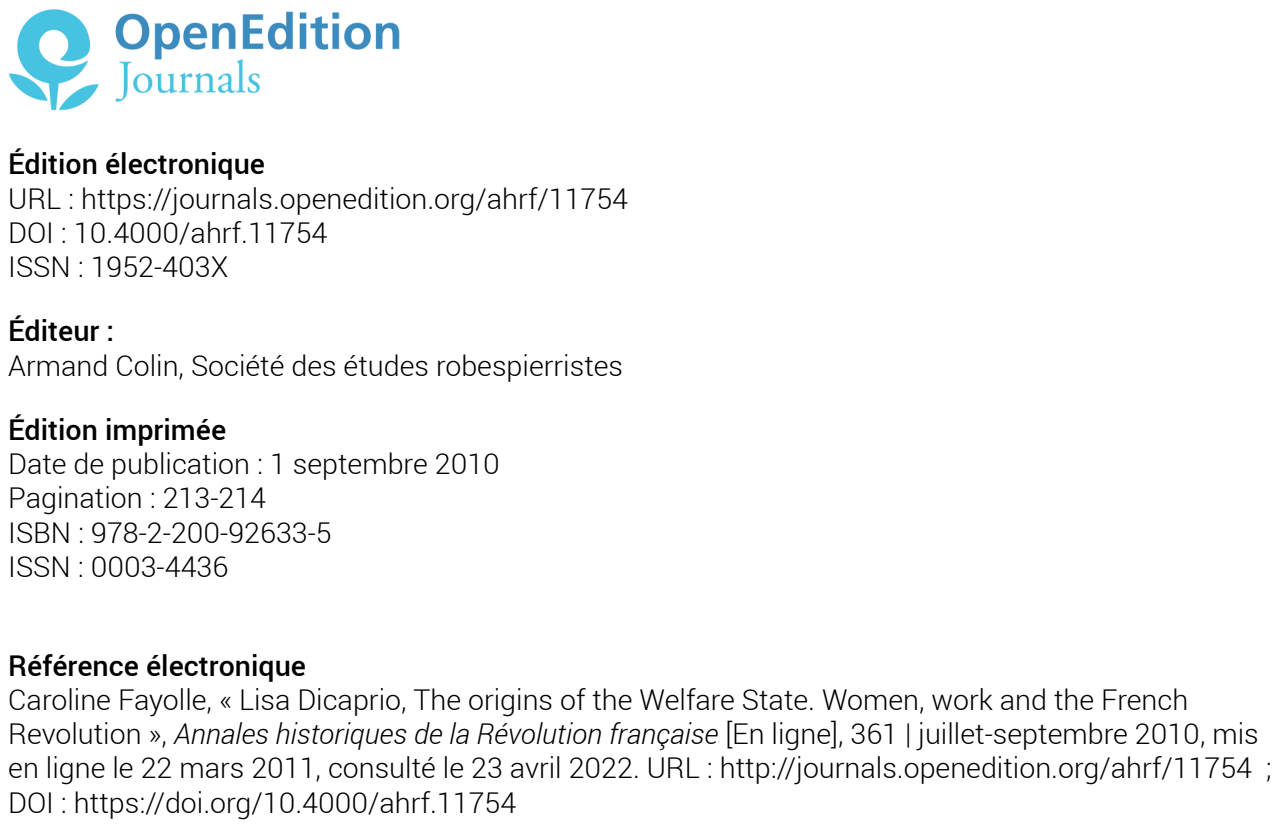

Ce document a été généré automatiquement le 23 avril 2022.

Tous droits réservés 


\title{
Lisa Dicaprio, The origins of the Welfare State. Women, work and the French Revolution
}

\author{
Caroline Fayolle
}

\section{RÉFÉRENCE}

Lisa Dicaprio, The origins of the Welfare State. Women, work and the French Revolution, Urbana and Chicago, University of Illinois Press, 2007, 288 p., ISBN 978-0-252-03021-5, 33.80€

1 Cet ouvrage de l'historienne américaine Lisa Dicaprio offre une réflexion stimulante sur la genèse révolutionnaire de l'État-Providence, et propose, dans la lignée des travaux de Dominique Godineau, de questionner sous l'angle du genre les rapports entretenus entre le travail et la citoyenneté. Pour cela, l'auteur se livre à une étude approfondie du fonctionnement des deux ateliers de filature établis par le décret du 30 mai 1790 de l'Assemblée nationale pour fournir du travail aux indigents de la capitale, principalement aux femmes mais aussi aux vieillards et aux enfants. Supprimés cinq ans plus tard par la Convention thermidorienne, ces ateliers constituent pour Lisa Dicaprio un point d'observation concret des politiques sociales menées de 1790 à 1795. S'appuyant notamment sur les archives des différents comités chargés de l'assistance publique, l'auteur souligne les réussites mais aussi les limites de ces politiques.

2 L'ouvrage s'organise selon un plan chronologique en quatre parties. Tout d'abord, Lisa Dicaprio évoque le Bureau de filature des pauvres sous l'Ancien Régime pour mieux mettre en relief la nouveauté du projet d'assistance publique révolutionnaire que l'auteur qualifie de moderne, laïc et centralisé. La seconde partie propose une immersion dans les ateliers de filature, depuis leur création jusqu'à l'an II, et expose plus particulièrement les conditions de travail des femmes. L'auteur souligne la contradiction entre les deux fonctions principales des ateliers, à savoir offrir un moyen 
de subsistance aux pauvres et générer du profit avec la vente des fils. Ce dernier but commercial, tout comme la volonté de ne pas détourner de la main-d'œuvre des manufactures privées, explique les rémunérations faibles dispensées dans les ateliers de filature publics. Ces dernières étaient de plus justifiées par une conception du travail des femmes comme un simple complément à l'emploi de leurs maris, ce qui maintenait les épouses dans une forme de dépendance économique et accentuait la précarité des veuves et des célibataires. C'est donc logiquement la question salariale qui suscita rapidement des contestations de la part des ouvrières. L'étude de ces conflits au sein des ateliers représente l'un des aspects les plus intéressants de l'ouvrage. S'inscrivant à la jonction de l'histoire politique et sociale, Lisa Dicaprio expose brillamment la progressive politisation des revendications ouvrières dans le contexte révolutionnaire. Loin de se concevoir comme des pauvres recevant la charité, ces femmes affirmèrent peu à peu un droit à la subsistance, dont la concrétisation fut perçue comme un devoir de l'Assemblée envers les citoyens actifs comme passifs.

Parce que le contexte militaire et politique de l'an II eut des incidences directes sur la gestion des ateliers de filature et sur les conflits qui l'animent, la troisième partie de l'ouvrage se concentre sur cette période. Les ateliers de filature furent alors mis au service des besoins de l'armée, ce qui impliqua de nouvelles exigences en termes de production. Cela n'empêcha pas les ouvrières d'intensifier la lutte pour obtenir l'augmentation des salaires. Dans leurs pétitions, ces dernières légitimèrent leurs demandes en évoquant désormais le départ des hommes à la guerre et le sacrifice que ces absences impliquaient pour elles et leur famille. Liées aux mouvements de la sansculotterie, elles portèrent leurs revendications auprès des sociétés populaires. La nature de leurs protestations et la multiplication de leurs interventions de l'automne 1793 au printemps 1794 invalide, selon Lisa Dicaprio, l'interprétation des historiens comme Joan Landes pour qui le décret Amar (octobre 1793) mettrait un terme à la participation des femmes à la vie politique. Ce serait moins le décret Amar que la réaction thermidorienne qui constituerait un réel tournant pour la vie des « citoyennes-ouvrières ». La dernière partie de l'ouvrage s'applique à le démontrer. Les décrets de l'an III relatifs à la suppression des ateliers de filature et à la généralisation $\mathrm{du}$ travail à domicile s'intègrent, pour l'auteur, dans un projet de démantèlement du système d'assistance publique centralisé mis en place les années précédentes. Les arguments pour légitimer cette politique d'abandon par le pouvoir central de ses responsabilités envers les plus pauvres sont analysés avec minutie. Ils relèvent à la fois d'une recherche de rentabilité économique et d'enjeux politiques, les ateliers étant perçus comme des foyers insurrectionnels. Annonçant la fameuse déclaration de Michelet, "L'ouvrière, mot impie ", les autorités de l'an III expriment leur méfiance envers ces travailleuses dont l'engagement politique transgresse les normes de genre. La volonté de les réassigner à leur foyer rappelle que la reconstruction de l'ordre social a impliqué une redéfinition des rôles sexués. Réévaluant la politique d'assistance publique menée par les premières années de la Révolution, l'étude passionnante de Lisa Dicaprio constitue un apport significatif à l'histoire politique du travail et des femmes en Révolution. 